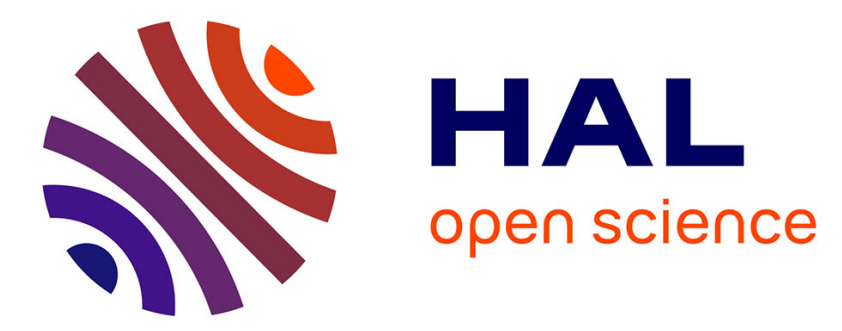

\title{
Roussouly's sagittal spino-pelvic morphotypes as determinants of gait in asymptomatic adult subjects.
}

Ziad Bakouny, Ayman Assi, Abir Massaad, Elie Saghbini, Virginie Lafage, Wafa Skalli, Ismat Ghanem, Gaby Kreichati

\section{- To cite this version:}

Ziad Bakouny, Ayman Assi, Abir Massaad, Elie Saghbini, Virginie Lafage, et al.. Roussouly's sagittal spino-pelvic morphotypes as determinants of gait in asymptomatic adult subjects.. Gait \& Posture, 2017, 54, pp.27-33. 10.1016/j.gaitpost.2017.02.018 . hal-02500555

\section{HAL Id: hal-02500555 \\ https://hal.science/hal-02500555}

Submitted on 6 Mar 2020

HAL is a multi-disciplinary open access archive for the deposit and dissemination of scientific research documents, whether they are published or not. The documents may come from teaching and research institutions in France or abroad, or from public or private research centers.
L'archive ouverte pluridisciplinaire HAL, est destinée au dépôt et à la diffusion de documents scientifiques de niveau recherche, publiés ou non, émanant des établissements d'enseignement et de recherche français ou étrangers, des laboratoires publics ou privés. 


\title{
Roussouly's sagittal spino-pelvic morphotypes as determinants of gait in asymptomatic adult subjects
}

\author{
Ziad Bakouny $^{\mathrm{a}}$, Ayman Assi ${ }^{\mathrm{a}, \mathrm{b}, *}$, Abir Massaad $^{\mathrm{a}}$, Elie Saghbini ${ }^{\mathrm{a}}$, Virginie Lafage ${ }^{\mathrm{c}}$, \\ Wafa Skalli $^{\mathrm{b}}$, Ismat Ghanem ${ }^{\mathrm{a}, \mathrm{d}}$, Gaby Kreichati ${ }^{\mathrm{a}, \mathrm{d}}$ \\ a Laboratory of Biomechanics and Medical Imaging, Faculty of Medicine, University of Saint-Joseph, Beirut, Lebanon \\ b Institut de Biomécanique Humaine Georges Charpak, Arts et Métiers ParisTech, Paris, France \\ ' Spine division, Hospital for Special Surgery, New York, USA \\ d Hôtel-Dieu de France Hospital, University of Saint-Joseph, Beirut, Lebanon
}

Keywords:

Sagittal alignment

Roussouly classification

Gait

Kinematics

Pelvic incidence

Lumbar lordosis

\begin{abstract}
A B S T R A C T
Sagittal alignment is known to greatly vary between asymptomatic adult subjects; however, there are no studies on the possible effect of these differences on gait. The aim of this study is to investigate whether asymptomatic adults with different Roussouly sagittal alignment morphotypes walk differently. Ninetyone asymptomatic young adults ( $46 \mathrm{M} \& 45 \mathrm{~W}$ ), aged $21.6 \pm 2.2$ years underwent 3D gait analysis and full body biplanar X-rays with three-dimensional (3D) reconstructions of their spines and pelvises and generation of sagittal alignment parameters. Subjects were divided according to Roussouly's sagittal alignment classification. Sagittal alignment and kinematic parameters were compared between Roussouly types. 17 subjects were classified as type 2, 47 as type 3, 26 as type 4 but only 1 as type 1 . Type 2 subjects had significantly more mean pelvic retroversion (less mean pelvic tilt) during gait compared to type 3 and 4 subjects (type $2: 8.2^{\circ}$; type $3: 11.2^{\circ}$, type $4: 11.3^{\circ}$ ) and significantly larger ROM pelvic obliquity compared to type 4 subjects (type $2: 11.0^{\circ}$; type $4: 9.1^{\circ}$ ). Type 2 subjects also had significantly larger maximal hip extension during stance compared to subjects of types 3 and 4 (type 2: $-11.9^{\circ}$; type $3:-8.8^{\circ}$; type $4:-7.9^{\circ}$ ) and a larger ROM of ankle plantar/dorsiflexion compared to type 4 subjects (type $2: 31.1^{\circ}$; type $4: 27.9^{\circ}$ ). Subjects with type 2 sagittal alignment were shown to have a gait pattern involving both increased hip extension and pelvic retroversion which could predispose to posterior femoroacetabular impingement and consequently osteoarthritis.
\end{abstract}

\section{Introduction}

Spinal deformities are common orthopedic problems in both children [1] and adults [2] which often affect the spine in all 3 planes. While the motive for treatment can be related to aesthetic considerations or pulmonary function deficiency [3], spinal anomalies have also been shown to affect gait and balance [4].

Previous studies based on gait analysis have shown a significant effect of frontal malalignment on the kinematics [5,6], kinetics [7], muscle activation patterns [6] and spatio-temporal characteristics $[5,8]$ of gait. However, there has recently been increased emphasis on the importance of the restoration of physiological sagittal alignment during spine deformity treatment [9].

\footnotetext{
* Corresponding author at: Laboratory of Biomechanics and Medical Imaging, Faculty of Medicine, Campus of Innovation and Sport, University of Saint-Joseph, Damascus street, PO Box 17-5208 Mar Mikhael, Beirut, 1104 2020, Lebanon.

E-mail addresses: ayman.assi@usj.edu.lb, ayman.assi@gmail.com (A. Assi).
}

Normative sagittal alignment requires a harmonious relationship between cervical lordosis, thoracic kyphosis, lumbar lordosis and pelvic parameters. While the absolute values of each of these components can vary in a large range of normality, these parameters are correlated amongst each other in order to maintain proper alignment in healthy subjects [10]. Roussouly et al. suggested that normal sagittal alignment could be divided into 4 types that differ significantly between each other [11]. While previous gait analysis studies have shown a significant effect of sagittal malalignment on gait [7,12-16], there are no studies on the relationship between the variations of normal alignment and gait in asymptomatic healthy subjects.

The aim of this study is to investigate whether asymptomatic healthy adults with different Roussouly sagittal alignment morphotypes walk differently. Our hypothesis was that the kinematics and spatio-temporal characteristics of gait differ between subjects with different sagittal alignment morphotypes. 


\section{Materials and methods}

\subsection{Study design}

This is a cross-sectional IRB approved study of the relationship between sagittal alignment and gait in young adult volunteers. The inclusion criteria were age between 18 and 28 years and no history of orthopedic surgery to either the spine, pelvis or lower limbs. Subjects were excluded if they presented any pain, including lower back pain, at the time of the study or if they had any musculoskeletal disease. Most subjects were students recruited at one of the faculties of our university. All subjects signed a written informed consent form.

\subsection{Data acquisition}

For each subject the following demographic characteristics were noted: age, gender, weight, height and body mass index (BMI).

Each subject underwent three-dimensional gait analysis (3DGA) using a Vicon ${ }^{\circledR}$ (Vicon Motion Systems, Oxford, UK) optoelectronic motion system (7 MX3 infrared cameras, $200 \mathrm{~Hz}$ ). Marker placement was based on the modified Helen Hayes protocol [17] and was applied as recommended in the Plug in Gait ${ }^{\circledR}$ model. Subjects were asked to walk at a self-selected speed along a $10-\mathrm{m}$ walkway. The consistency of the kinematic curves was verified under Polygon ${ }^{\circledR}$ (Vicon Motion Systems, Oxford, UK) and inconsistent trials were eliminated. One representative trial was then used to calculate three-dimensional joint angles and spatio-temporal parameters. Data was processed using the pipeline in Workstation ${ }^{\circledR}$ (Vicon Motion Systems, Oxford, UK): fill gap routine \pm 10 frames and Woltring filter with a scale of 10 .
Kinematic parameters of the pelvis, hip, knee and ankle were then calculated in Matlab ${ }^{\circledR}$ (Mathworks, Natick, USA) for each subject. The following spatio-temporal parameters were calculated by the model: walking speed ( $\mathrm{m} / \mathrm{s}$ ), cadence (steps/min), foot off (\% of gait cycle), single support (s) and step length (m). Single support was normalized to stride time and was thus expressed as a percentage of the whole gait cycle. All the kinematic and spatio-temporal gait parameters generated in this study have been previously defined $[18,19]$.

All subjects also underwent a full body biplanar X-ray exam (EOS Imaging, Paris, France). Subjects were asked to stand upright in a relaxed manner with their shoulders flexed to about $45^{\circ}$ and their hands placed on the zygomatic bones of their face. This consensual free-standing position $[10,20]$ was adopted in order to avoid the superimposition of subjects' arms over their spines on lateral radiographs.

Their spines, pelvises and lower limbs were reconstructed in 3D using SterEOS ${ }^{\circledR}$ (EOS Imaging, Paris, France). Lower limb length (in meters) was measured on the $3 \mathrm{D}$ reconstructions of the lower limbs, as the sum of the lengths of the femur (from the center of the femoral head to the middle of the intercondylar region of the distal femur) and tibia (from the middle of the intercondylar region of the proximal tibia to the middle of the horizontal portion of the medial malleolus). Furthermore, the following, previously defined [21,22], sagittal spino-pelvic alignment parameters were generated from these 3D reconstructions: pelvic tilt, sacral slope, pelvic incidence, L1-L5 lordosis, L1-S1 lordosis, T1-T12 kyphosis and T4T12 kyphosis. Briefly, pelvic tilt is defined as the angle between the vertical and a line drawn from the center of the femoral heads to the midpoint of the sacral plate; sacral slope as the angle between the $\mathrm{S} 1$ sacral endplate and the horizontal; pelvic incidence as the angle between the perpendicular to the sacral plate and a line

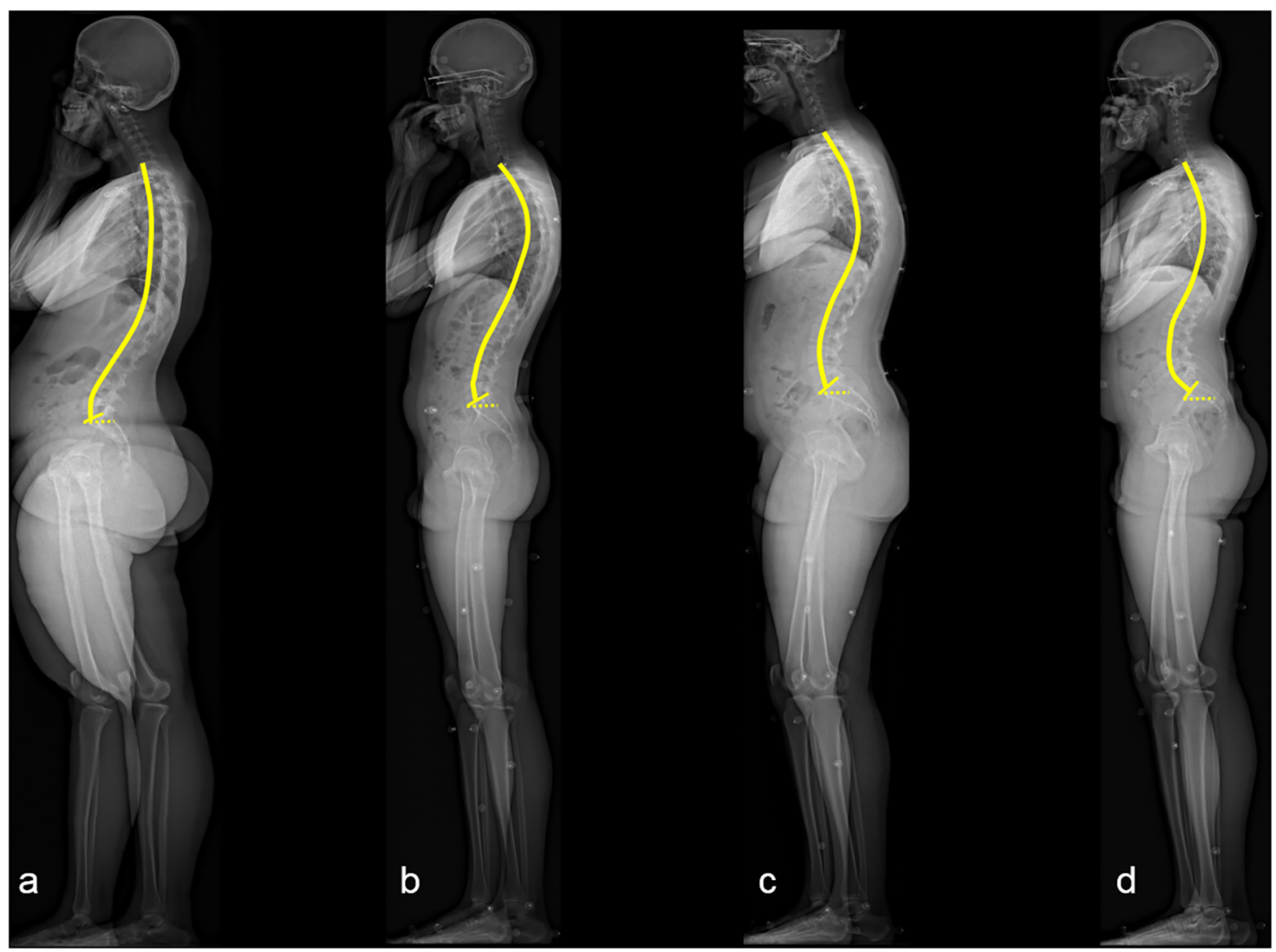

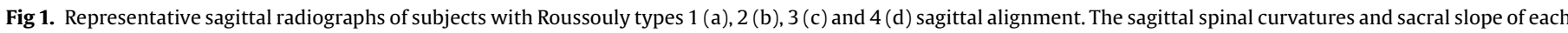

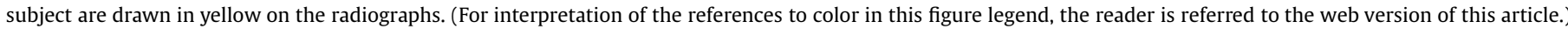


drawn from the center of the femoral heads to the midpoint of the sacral plate; L1-L5 and L1-S1 lordosis as the angles between the upper endplate of L1 and the lower endplate of L5 or upper endplate of S1 respectively; T1-T12 and T4-T12 kyphosis as the angles between the upper endplate of T1 or T4 (respectively) and the lower endplate of T12.

In the rest of this report, the term "gait pelvic tilt" will be used to refer to the movement of the anterior superior iliac spines (ASIS) relative to the posterior superior iliac spines (PSIS), the value of this variable increases with anteversion and decreases with retroversion. Whereas "radiographic pelvic tilt" will be used in order to refer to the radiographic definition of pelvic tilt, the value of this variable increases with retroversion and decreases with anteversion.

\subsection{Statistical analysis}

Each subject was classified into one of the 4 types of Roussouly [11]: type 1 subjects had a SS $<35^{\circ}$ with 3 vertebrae or less in their lumbar lordosis, type 2 subjects had $\mathrm{SS}<35^{\circ}$ with more than 3 vertebrae in their lumbar lordosis, type 3 subjects had $35^{\circ} \leq \mathrm{SS}$ $<45^{\circ}$ and type 4 subjects had $\mathrm{SS} \geq 45^{\circ}$. Sagittal radiographs of subjects that are representative of Roussouly types 1, 2, 3 and 4 are represented in Fig. 1.

Statistical analysis was done using SPSS Statistics version 20.0 (IBM Corporation, New York, USA) and Xlstat version 2015.3.1 (Addinsoft, Paris, France). All variables were tested for normality using the Shapiro-Wilk test and for equality of variance using Levene's test. The anthropometric, spino-pelvic, kinematic and spatio-temporal parameters were compared between Roussouly types: normally distributed variables were compared by one-way analysis of variance (ANOVA) with Games-Howell (for samples with unequal variance) or Hochberg's T2 (for samples with equal variance but unequal sample sizes) tests as post hoc analysis; nonnormally distributed variables were compared using KruskallWallis test with Conover-Iman post hoc analysis and Bonferroni correction. Chi-squared test was used to compare the male/female ratio between Roussouly types. Step length and walking speed were compared between Roussouly types while adjusting for lower limb length and BMI using one-way analysis of covariance (ANCOVA) followed by Dunn-Šidák pairwise comparisons. Step length was also compared between the right and left limbs, for each Roussouly type, while controlling for lower limb length using ANCOVA. The significance level was set at 0.05 for all tests.

\section{Results}

\subsection{Subject demographics}

Ninety-one asymptomatic young adults ( 46 men \& 45 women), aged $21.6 \pm 2.2(18-28)$ years, were enrolled in this study.

\subsection{Subject characteristics by Roussouly type}

$17(18.7 \%)$ subjects were classified as type 2, 47 (51.6\%) as type 3 , $26(28.6 \%)$ as type 4 , and only $1(1.1 \%)$ subject as type 1 . Therefore, Roussouly's type 1 was excluded from further analysis. The demographic and sagittal alignment characteristics of each Roussouly type are reported in Table 1 . Type 4 subjects were significantly more overweight compared to type 2 subjects (BMI $=24.2 \pm 3.0$ vs. $22.5 \pm 2.5 \mathrm{~kg} / \mathrm{m}^{2} ; \mathrm{p}=0.017$ ) but all types had similar age and height. Moreover, both genders were similarly distributed amongst all 3 types. Subjects classified into different Roussouly types had similar T1-T12 \& T4-T12 kyphosis and radiographic pelvic tilt.

\subsection{Gait differences between Roussouly types}

The kinematic curves of the 3 Roussouly types are drawn in Fig. 2. In almost all of the kinematic curves there is an offset between the 3 curves which are otherwise mostly parallel. While all 3 types noticeably differ between each other in all of the curves, type 2 subjects in particular had a quite distinct gait pattern compared to subjects of types 3 and 4 . The comparison of kinematic and spatio-temporal parameters across the 3 Roussouly types (Table 2) revealed: Type 2 subjects had a significantly more retroverted pelvis during gait (decreased gait pelvic tilt) compared to type 3 and 4 subjects and significantly larger mobility of their pelvises in the frontal plane compared to type 4 subjects. Type 2 subjects also had significantly larger maximal hip extension during stance compared to subjects of types 3 and 4 and a larger mobility of their ankle in the sagittal plane compared to type 4 subjects. The times of maximal knee flexion during swing and maximal dorsiflexion during stance phase occurred at later stages during the gait of type 4 subjects compared to subjects of types 2 and 3 (only significant for the time of maximal dorsiflexion during stance). None of the spatio-temporal parameters significantly differed between Roussouly types. Furthermore, when step lengths were compared between the right and left limbs, while controlling for lower limb length, they were found to be similar for Roussouly's

Table 1

Subject characteristics by Roussouly type.

\begin{tabular}{|c|c|c|c|c|}
\hline & $\begin{array}{l}\text { Type } 2 \\
(\mathrm{~N}=17)\end{array}$ & $\begin{array}{l}\text { Type } 3 \\
(\mathrm{~N}=47)\end{array}$ & $\begin{array}{l}\text { Type } 4 \\
(\mathrm{~N}=26)\end{array}$ & Between-group comparison (p-value) \\
\hline Age (years) & $21.8 \pm 2.7$ & $21.5 \pm 2.2$ & $21.6 \pm 1.8$ & 0.795 \\
\hline Gender & $7 \mathrm{M} / 10 \mathrm{~W}$ & $23 \mathrm{M} / 24 \mathrm{~W}$ & $16 \mathrm{M} / 10 \mathrm{~W}$ & 0.388 \\
\hline Weight (Kg) & $65.5 \pm 12.8$ & $67.9 \pm 15.6$ & $71.9 \pm 13.6$ & 0.062 \\
\hline Height (m) & $1.70 \pm 0.09$ & $1.70 \pm 0.11$ & $1.72 \pm 0.09$ & 0.423 \\
\hline $\mathrm{BMI}\left(\mathrm{Kg} / \mathrm{m}^{2}\right)$ & $22.5 \pm 2.5^{c}$ & $23.2 \pm 3.2$ & $24.2 \pm 3.0^{\mathrm{a}}$ & $0.017^{d}$ \\
\hline T1-T12 kyphosis $\left({ }^{\circ}\right)$ & $-45.3 \pm 9.9$ & $-46.3 \pm 9.2$ & $-45.2 \pm 7.8$ & 0.691 \\
\hline T4-T4 kyphosis $\left({ }^{\circ}\right)$ & $-38.7 \pm 10.2$ & $-38.5 \pm 9.4$ & $-37.1 \pm 7.2$ & 0.589 \\
\hline L1-L5 lordosis $\left(^{\circ}\right)$ & $38.5 \pm 5.9^{\mathrm{b}, \mathrm{c}}$ & $47.6 \pm 7.9^{\mathrm{a}, \mathrm{c}}$ & $53.9 \pm 12.7^{\mathrm{a}, \mathrm{b}}$ & $<\mathbf{0 . 0 0 1}^{\mathrm{d}}$ \\
\hline $\mathrm{L} 1-\mathrm{S} 1$ lordosis $\left({ }^{\circ}\right)$ & $50.5 \pm 7.4^{\mathrm{b}, \mathrm{c}}$ & $60.1 \pm 6.3^{a, c}$ & $66.9 \pm 11.5^{\mathrm{a}, \mathrm{b}}$ & $<\mathbf{0 . 0 0 1}^{\mathrm{d}}$ \\
\hline Pelvic incidence $\left({ }^{\circ}\right)$ & $41.1 \pm 7.8^{\mathrm{b}, \mathrm{c}}$ & $48.1 \pm 7.2^{\mathrm{a}, \mathrm{c}}$ & $56.7 \pm 12.7^{\mathrm{a}, \mathrm{b}}$ & $<\mathbf{0 . 0 0 1}^{\mathrm{d}}$ \\
\hline Sacral slope $\left(^{\circ}\right)$ & $30.0 \pm 5.0^{\mathrm{b}, \mathrm{c}}$ & $38.3 \pm 3.8^{\mathrm{a}, \mathrm{c}}$ & $45.6 \pm 8.5^{\mathrm{a}, \mathrm{b}}$ & $<\mathbf{0 . 0 0 1}^{\mathrm{d}}$ \\
\hline Radiographic pelvic tilt $\left({ }^{\circ}\right)$ & $10.9 \pm 5.1$ & $9.7 \pm 6.1$ & $11.0 \pm 7.5$ & 0.171 \\
\hline
\end{tabular}

M: Men/W: Women.

a Significantly different from type 2 .

b Significantly different from type 3 .

c Significantly different from type 4 .

d Significant at the $\mathrm{p}<0.05$ level. 

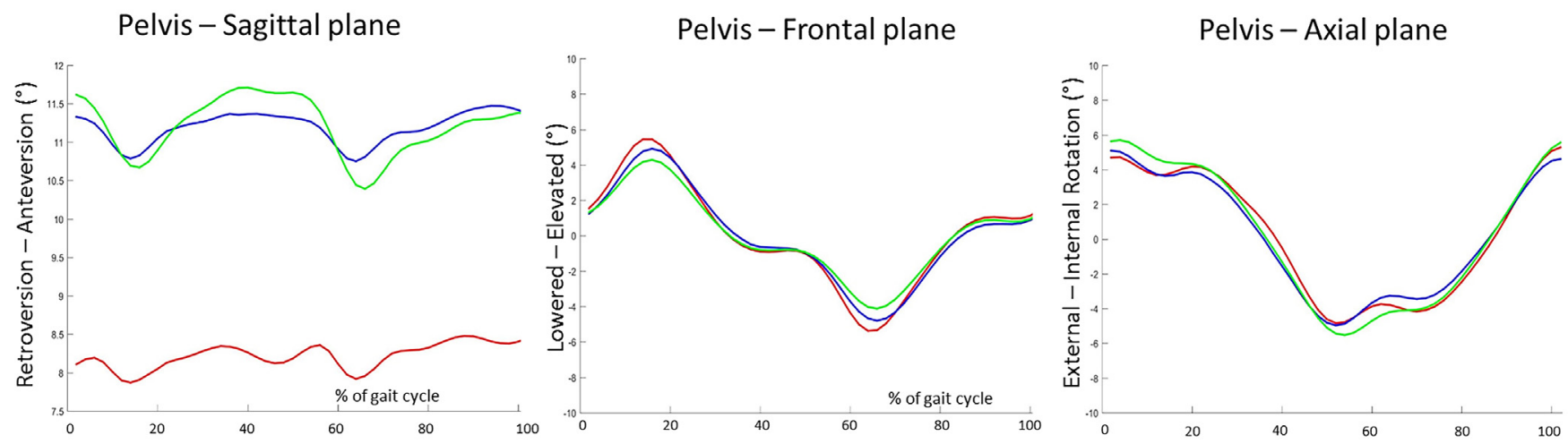

Hip - Sagittal plane

Hip - Frontal plane
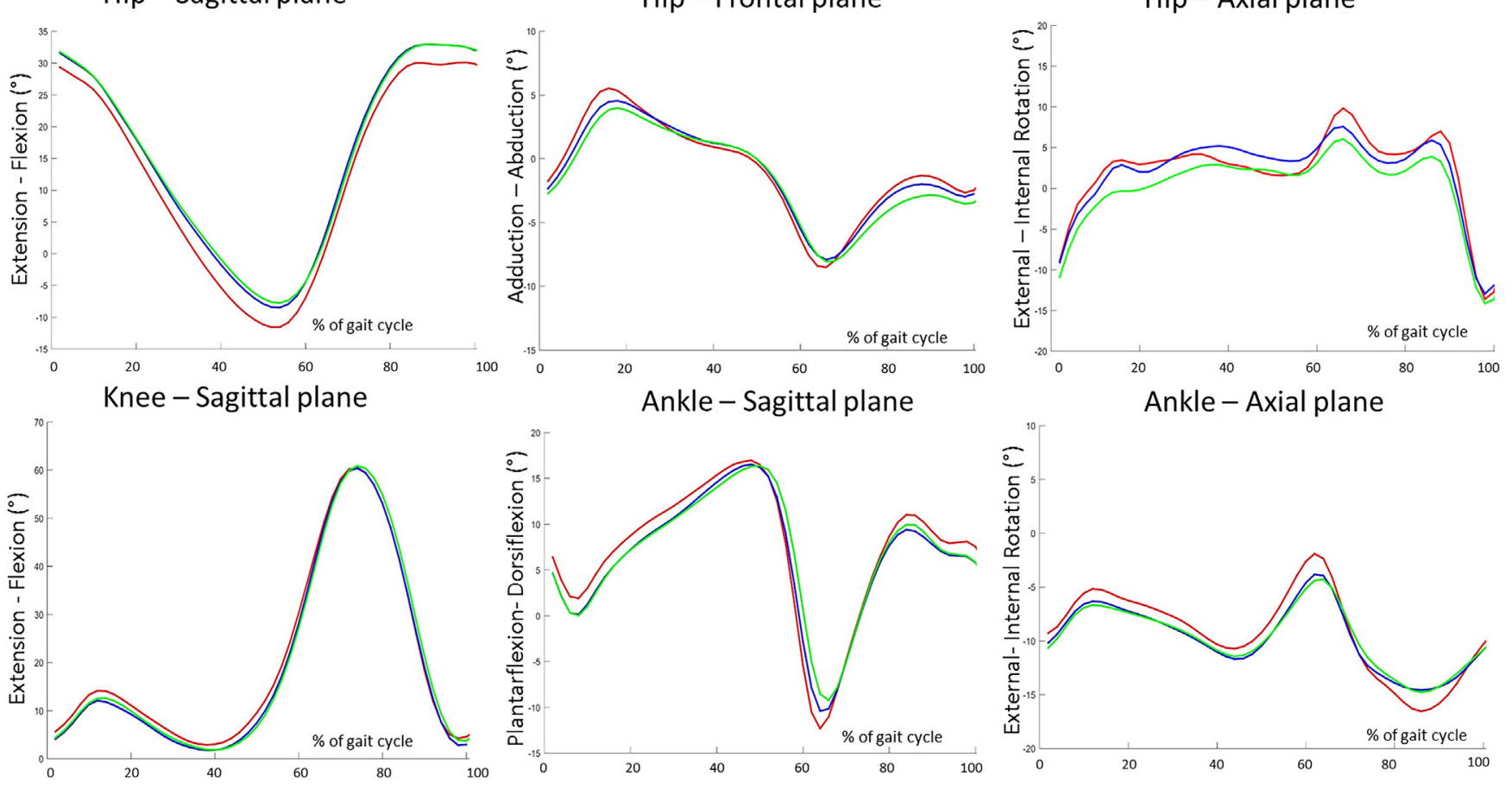

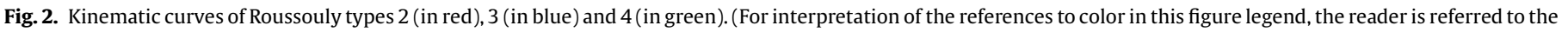
web version of this article.)

type $2(p=0.282)$, type $3(p=0.372)$ and type $4(p=0.691)$. Fig. 3 summarizes the most relevant gait differences in the sagittal plane between the Roussouly types.

\section{Discussion}

In this study, the examination of the sagittal alignment and gait of 91 asymptomatic adults showed that subjects with different Roussouly morphotypes tend to have different gait kinematics but similar spatio-temporal characteristics of gait. Each sagittal alignment morphotype was associated with a gait pattern which varied from the two other morphotypes, suggesting that corridors of normality could be specific to sagittal alignment profiles.

\subsection{Subject characteristics by Roussouly type}

In the current study, only 1 out of 91 subjects (1.1\%) was classified as having type 1 sagittal alignment. This is in contrast with Roussouly's study [11] in which $21.3 \%$ of asymptomatic subjects had been classified as type 1 but somewhat in accordance with a larger study on 489 subjects by Araujo et al. in which only
4.9\% of subjects had been classified as having type 1 sagittal alignment [23]. Furthermore, Araujo et al.'s study [23] had demonstrated that housewives and obese subjects were more likely to have type 1 sagittal alignment. This could therefore further explain the low prevalence of this type in our population since most of the subjects recruited in this study were university students and the mean BMI (Table 1) was well below the threshold of obesity $\left(\mathrm{BMI}=30 \mathrm{~kg} / \mathrm{m}^{2}\right)$. Other factors could have resulted in the lack of subjects with type 1 alignment in our sample such as the young age of our participants, which is also a factor that is known to significantly influence sagittal alignment patterns [24] in asymptomatic adults. Type 4 subjects were significantly more overweight compared to type 2 subjects. The mean BMI of type 4 subjects $\left(24.2 \mathrm{~kg} / \mathrm{m}^{2}\right)$ was close to the threshold above which subjects are considered overweight $\left(25 \mathrm{~kg} / \mathrm{m}^{2}<\mathrm{BMI} \leq 30 \mathrm{~kg} / \mathrm{m}^{2}\right)$. This is in accordance with previous studies that had shown that while obese subjects were more likely to have type 1 sagittal alignment, overweight subjects were most likely to have type 4 sagittal alignment [23]. While pelvic incidence, sacral slope, radiographic pelvic tilt, L1-L5 and L1-S1 lordosis were all found to be significantly different between the 3 studied types, T1-T12 and 
Table 2

Gait comparisons between Roussouly types.

\begin{tabular}{|c|c|c|c|c|}
\hline & $\begin{array}{l}\text { Type } 2 \\
(\mathrm{~N}=17)\end{array}$ & $\begin{array}{l}\text { Type } 3 \\
(\mathrm{~N}=47)\end{array}$ & $\begin{array}{l}\text { Type } 4 \\
(\mathrm{~N}=26)\end{array}$ & $\begin{array}{l}\text { Between-group comparison } \\
\text { (p-value) }\end{array}$ \\
\hline \multicolumn{5}{|l|}{ Pelvis \& hip kinematics } \\
\hline Mean gait pelvic tilt $\left(^{\circ}\right)$ & $8.2 \pm 4.3^{\mathrm{b}, \mathrm{c}}$ & $11.2 \pm 5.9^{\mathrm{a}}$ & $11.3 \pm 5.3^{\mathrm{a}}$ & $\mathbf{0 . 0 2 4} 4^{\mathrm{e}}$ \\
\hline ROM pelvic obliquity $\left({ }^{\circ}\right)$ & $11.0 \pm 3.6^{\mathrm{c}}$ & $10.0 \pm 4.0$ & $9.1 \pm 4.9^{\mathrm{a}}$ & $0.034^{\mathrm{e}}$ \\
\hline ROM pelvic rotation $\left({ }^{\circ}\right)$ & $12.1 \pm 5.0$ & $12.1 \pm 4.6$ & $14.0 \pm 5.7$ & 0.088 \\
\hline ROM hip flexion/extension $\left({ }^{\circ}\right)$ & $44.0 \pm 3.2$ & $43.4 \pm 3.9$ & $42.8 \pm 4.3$ & 0.381 \\
\hline Mean hip flexion/extension $\left({ }^{\circ}\right)$ & $12.3 \pm 4.4$ & $15.1 \pm 6.7$ & $15.5 \pm 6.5$ & 0.055 \\
\hline Hip flexion at initial contact $\left({ }^{\circ}\right)$ & $29.8 \pm 4.4$ & $32.5 \pm 6.9$ & $32.6 \pm 6.8$ & 0.088 \\
\hline Maximum hip extension in stance $\left(^{\circ}\right)$ & $-11.9 \pm 4.4^{\mathrm{b}, \mathrm{c}}$ & $-8.8 \pm 7.1^{\mathrm{a}}$ & $-7.9 \pm 6.4^{\mathrm{a}}$ & $0.020^{\mathrm{e}}$ \\
\hline Time of maximum hip extension in stance (\%) & $52.2 \pm 1.8$ & $52.4 \pm 1.8$ & $52.4 \pm 1.9$ & 0.856 \\
\hline ROM hip abduction/adduction $\left({ }^{\circ}\right)$ & $14.3 \pm 4.1$ & $13.3 \pm 3.6$ & $13.0 \pm 4.2$ & 0.175 \\
\hline ROM hip internal/external rotation $\left(^{\circ}\right)$ & $30.1 \pm 10.3$ & $28.3 \pm 9.2$ & $27.3 \pm 9.1$ & 0.528 \\
\hline Hip rotation at initial contact $\left(^{\circ}\right)$ & $-10.4 \pm 10.2$ & $-12.4 \pm 9.3$ & $-14.2 \pm 9.4$ & 0.204 \\
\hline \multicolumn{5}{|l|}{ Knee kinematics } \\
\hline ROM knee flexion/extension $\left(^{\circ}\right)$ & $60.6 \pm 6.2$ & $61.4 \pm 5.5$ & $61.3 \pm 4.6$ & 0.748 \\
\hline Maximum knee flexion in stance $\left(^{\circ}\right)$ & $14.7 \pm 6.0$ & $12.7 \pm 7.5$ & $13.5 \pm 6.0$ & 0.371 \\
\hline Time of maximum knee flexion in stance (\%) & $12.7 \pm 2.3$ & $12.9 \pm 2.3$ & $13.5 \pm 2.2$ & 0.223 \\
\hline Maximum knee extension in stance $\left(^{\circ}\right)$ & $1.8 \pm 4.3$ & $0.7 \pm 4.3$ & $1.4 \pm 4.7$ & 0.366 \\
\hline Time of maximum knee extension in stance (\%) & $35.8 \pm 5.9$ & $36.2 \pm 6.1$ & $37.5 \pm 5.2$ & 0.264 \\
\hline Maximum knee flexion in swing $\left(^{\circ}\right)$ & $60.7 \pm 7.2$ & $61.0 \pm 5.8$ & $61.7 \pm 4.3$ & 0.667 \\
\hline Time of maximum knee flexion in swing (\%) & $71.9 \pm 1.5^{c}$ & $72.2 \pm 1.6$ & $72.7 \pm 1.3^{\mathrm{a}}$ & 0.028 \\
\hline Knee extension at initial contact $\left({ }^{\circ}\right)$ & $3.9 \pm 6.1$ & $3.1 \pm 4.8$ & $3.5 \pm 3.8$ & 0.687 \\
\hline \multicolumn{5}{|l|}{ Ankle kinematics } \\
\hline ROM dorsiflexion/plantarflexion $\left({ }^{\circ}\right)$ & $31.1 \pm 4.8^{\mathrm{c}}$ & $28.9 \pm 5.1$ & $27.9 \pm 5.8^{\mathrm{a}}$ & $0.013^{\mathrm{e}}$ \\
\hline Maximum dorsiflexion in stance $\left(^{\circ}\right)$ & $17.6 \pm 3.8$ & $17.1 \pm 3.2$ & $17.3 \pm 3.6$ & 0.753 \\
\hline Time of maximum dorsiflexion in stance (\%) & $45.7 \pm 3.9^{d}$ & $46.6 \pm 3.6^{\mathrm{d}}$ & $48.1 \pm 3.3^{\mathrm{a}, \mathrm{b}}$ & $\mathbf{0 . 0 0 2}{ }^{\mathrm{e}}$ \\
\hline Maximum plantarflexion in stance $\left(^{\circ}\right)$ & $-9.1 \pm 6.1$ & $-7.8 \pm 5.1$ & $-6.6 \pm 5.3$ & 0.112 \\
\hline Time of maximum plantarflexion in stance (\%) & $60.3 \pm 1.4$ & $60.4 \pm 1.8$ & $60.8 \pm 1.8$ & 0.311 \\
\hline Maximum dorsiflexion in swing $\left(^{\circ}\right)$ & $11.2 \pm 3.7$ & $10.0 \pm 2.7$ & $10.6 \pm 3.5$ & 0.146 \\
\hline Time of maximum dorsiflexion in swing (\%) & $83.7 \pm 2.9$ & $84.8 \pm 4.9$ & $84.1 \pm 4.0$ & 0.873 \\
\hline ROM foot progression in stance $\left(^{\circ}\right)$ & $10.3 \pm 2.8$ & $9.7 \pm 3.1$ & $9.7 \pm 3.1$ & 0.498 \\
\hline \multicolumn{5}{|l|}{ Spatio-temporal parameters } \\
\hline Walking Speed $(\mathrm{m} / \mathrm{s})^{\mathrm{d}}$ & $1.29 \pm 0.15$ & $1.28 \pm 0.14$ & $1.26 \pm 0.15$ & 0.567 \\
\hline Cadence (steps/min) & $114.8 \pm 7.3$ & $114.7 \pm 8.3$ & $112.7 \pm 9.5$ & 0.654 \\
\hline Foot Off $(\%)$ & $60.2 \pm 1.4$ & $60.4 \pm 1.8$ & $60.8 \pm 1.7$ & 0.236 \\
\hline Normalized single support (\%) & $0.418 \pm 0.02$ & $0.415 \pm 0.02$ & $0.420 \pm 0.03$ & 0.696 \\
\hline Step length $(\mathrm{m})^{\mathrm{d}}$ & $0.679 \pm 0.05$ & $0.667 \pm 0.05$ & $0.661 \pm 0.05$ & 0.241 \\
\hline
\end{tabular}

a Significantly different from type 2 .

b Significantly different from type 3.

c Significantly different from type 4 .

d For step length and walking speed, comparisons were adjusted for BMI and step length.

e Significant at the $\mathrm{p}<0.05$ level.

T4-T12 kyphosis were found to be similar across types of sagittal alignment. This is in accordance with previous studies, which had reported significant differences in lumbar lordosis and pelvic parameters between Roussouly types [23] and only small correlations between these parameters and thoracic kyphosis $[10,25]$.

\subsection{Gait differences between Roussouly types}

This is the first study to show that healthy asymptomatic subjects with different sagittal alignment morphotypes tend to have mildly varied gait kinematics. Subjects with type 2 sagittal alignment, characterized by a hypolordotic spine with a small sacral slope [11], were found to have increased pelvic retroversion during gait (small gait pelvic tilt) compared to subjects with other sagittal alignment profiles. This is in contrast with the values of radiographic pelvic tilt of these same subjects, where type 2 subjects had similar pelvic retroversion compared to subjects with other types of sagittal alignment (Table 1). This suggests that radiographic pelvic tilt, which is measured on static X-rays, is not indicative of gait pelvic tilt that seems to significantly vary from its original static value during gait. Radiographic pelvic tilt is considered a crucial compensatory mechanism for subjects with sagittal malalignment and the maximal amount of pelvic tilt that a subject can perform is known to be limited by his maximal capacity of hip extension [9]. Therefore, the previous finding would suggest that the manner in which pelvic tilt changes during gait does not, at least solely, depend upon its value in the static position and that the general alignment of the subject partially determines this change during gait. Clinicians should thus not only consider the static value of pelvic tilt but also take into account that this value will change during gait depending on the subject's global alignment and that subjects with type 2 alignment would necessitate more pelvic retroversion during gait compared to other subjects.

Moreover, although subjects with type 2 alignment had similar spatio-temporal characteristics of gait compared to subjects with other sagittal morphotypes, they had increased maximal hip extension during stance and a larger Range of Motion (ROM) of ankle plantar/dorsiflexion during gait compared to other morphotypes (only significant compared to type 4 subjects for ankle plantar/dorsiflexion). This suggests that type 2 subjects necessitate more extension at the level of the hip and more ROM at the level of their ankles in order to walk at self-selected speed, compared to other subjects. Furthermore, although not statistically significant, type 2 subjects also had less mean hip flexion during the whole gait 

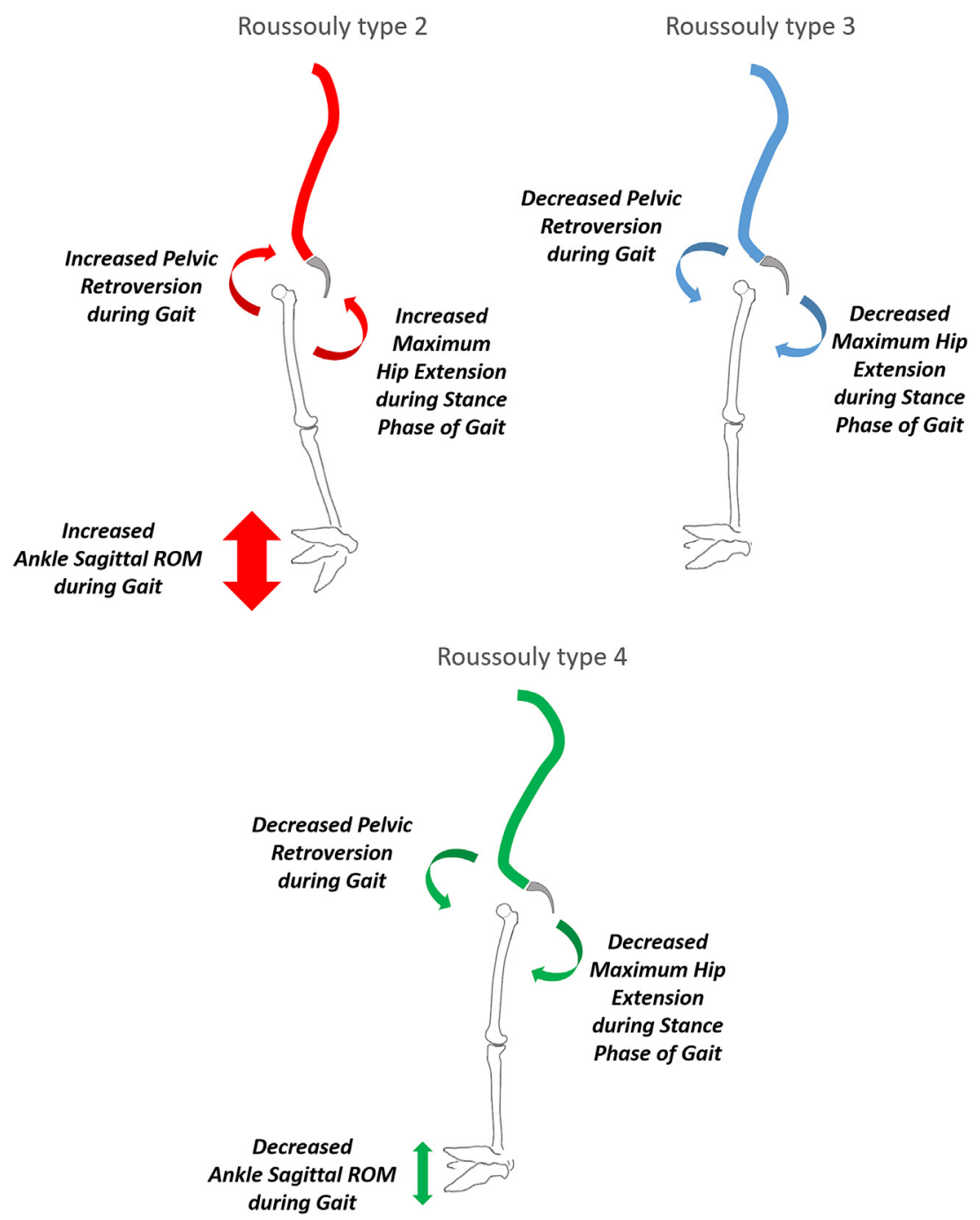

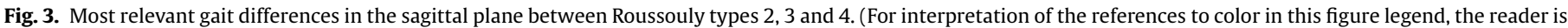
referred to the web version of this article.)

cycle $(p=0.055)$ and less hip flexion at initial contact $(p=0.088)$ compared to subjects with other sagittal alignment morphotypes (Table 2). This is also apparent in the kinematic curves of the hip in the sagittal plane (Fig. 2) where the mean curve of type 2 subjects was shifted downward (more extension) compared to the curves of the two other types, throughout the gait cycle. Since even mild to moderate hip osteoarthritis is known to limit the ability of subjects to perform hip extension [26], subjects with type 2 alignment would thus be more functionally affected compared to others by hip osteoarthritis, even if mild, during gait. Moreover, this finding of increased hip extension throughout the gait cycle, coupled with the increased retroversion of the pelvis (with the ensuing posterior overcoverage of the femoral head by the acetabulum) could lead to posterior femoroacetabular impingement and consequently hip osteoarthritis [27].

Interestingly, none of the previous studies on subjects with sagittal malalignment had reported a similar gait pattern to the ones reported in this study for any of the alignment types $[12,14,15]$. However, a study by Sarwahi et al. had also suggested that the gait anomalies resulting from sagittal malalignment (notably "flatback") could be a predisposing factor in the development of hip osteoarthritis [15].

Furthermore, the presence of significant differences in gait kinematics between asymptomatic subjects with different sagittal alignment profiles suggests that kinematic corridors of normality could be specific to each sagittal alignment profile. Otherwise, differences in gait kinematics between subjects with various pathologies and asymptomatic subjects that would have been significant could be underestimated (or non-significant differences could be overestimated).

The main limitation of this study is the lack of subjects with type 1 sagittal alignment. These subjects are known to have a peculiar pattern of sagittal alignment compared to other subjects and future studies should study their gait. Although multiple differences in kinematic parameters were statistically significant, the mean differences in angular values were fairly small for some of these parameters which therefore limits their clinical relevance. Furthermore, this study only compared kinematic curves using parameters that are commonly utilized in clinical practice. This approach to kinematic curve analysis was used in order to make the study as relevant as possible to clinicians. Future studies could use whole curve analysis methods in order to better characterize the full differences between such curves.

In conclusion, asymptomatic subjects with different types of sagittal alignment were shown to have mildly different patterns of gait kinematics but similar spatio-temporal characteristics of gait. This suggests that kinematic corridors of normality should be specific of sagittal alignment profiles. Moreover, subjects with type 
2 sagittal alignment were shown to have a gait pattern involving both increased hip extension and pelvic retroversion. This gait pattern could be a predisposing factor in the development of multiple musculoskeletal pathologies, among which posterior femoroacetabular impingement and consequently osteoarthritis.

\section{Conflict of interest statement}

\section{No conflicts of interest.}

\section{IRB approval}

This study has been approved by the institutional review board of our institution (number FM189/CE-HDF-285).

\section{Acknowledgements:}

This study was supported by the research council of the University of Saint-Joseph (grant number: FM189).

The study sponsors were involved in neither the study design, collection, analysis and interpretation of data nor in the writing of the manuscript; nor in the decision to submit the manuscript for publication.

\section{References}

[1] M.R. Konieczny, H. Senyurt, R. Krauspe, Epidemiology of adolescent idiopathic scoliosis, J. Child. Orthop. 7 (2013) 3-9, doi:http://dx.doi.org/10.1007/s11832012-0457-4.

[2] F. Schwab, A. Dubey, L. Gamez, A.B. El Fegoun, K. Hwang, M. Pagala, J.P. Farcy, Adult scoliosis: prevalence, SF-36, and nutritional parameters in an elderly volunteer population, Spine (Phila. Pa. 1976) 30 (2005) 1082-1085, doi:http:// dx.doi.org/10.1097/01.brs.0000160842.43482.cd.

[3] M.T. Hresko, Idiopathic scoliosis in adolescents, N. Engl. J. Med. 368 (2013) 834-841, doi:http://dx.doi.org/10.1056/NEJMcp1209063.

[4] S. Negrini, T.B. Grivas, T. Kotwicki, T. Maruyama, M. Rigo, H.R. Weiss, Why do we treat adolescent idiopathic scoliosis? What we want to obtain and to avoid for our patients. SOSORT 2005 consensus paper, Scoliosis 1 (4) (2006), doi: http://dx.doi.org/10.1186/1748-7161-1-4.

[5] M. Syczewska, K. Graff, M. Kalinowska, E. Szczerbik, J. Domaniecki, Influence of the structural deformity of the spine on the gait pathology in scoliotic patients, Gait Posture 35 (2012) 209-213, doi:http://dx.doi.org/10.1016/j. gaitpost.2011.09.008

[6] P. Mahaudens, X. Banse, M. Mousny, C. Detrembleur, Gait in adolescen idiopathic scoliosis: kinematics and electromyographic analysis, Eur. Spine ]. 18 (2009) 512-521, doi:http://dx.doi.org/10.1007/s00586-009-0899-7.

[7] J.C. Paul, A. Patel, K. Bianco, E. Godwin, Q. Naziri, S. Maier, V. Lafage, C. Paulino, T.J. Errico, Gait stability improvement after fusion surgery for adolescent idiopathic scoliosis is influenced by corrective measures in coronal and sagittal planes, Gait Posture 40 (2014) 510-515, doi:http://dx.doi.org/10.1016/j. gaitpost.2014.06.006.

[8] L.G. Lenke, J.R. Engsberg, S.A. Ross, A. Reitenbach, K. Blanke, K.H. Bridwell, Prospective dynamic functional evaluation of gait and spinal balance following spinal fusion in adolescent idiopathic scoliosis, Spine (Phila. Pa. 1976) 26 (2001) E330-E337, doi:http://dx.doi.org/10.1097/00007632-20010715000020.

[9] F. Schwab, A. Patel, B. Ungar, J. Farcy, V. Lafage, Adult spinal deformitypostoperative standing imbalance: how much can you tolerate? An overview of key parameters in assessing alignment and planning corrective surgery, Spine 35 (2010) 2224-2231, doi:http://dx.doi.org/10.1097 BRS.0b013e3181ee6bd4.
[10] R. Vialle, N. Levassor, L. Rillardon, A. Templier, W. Skalli, P. Guigui, Radiographic analysis of the sagittal alignment and balance of the spine in asymptomatic subjects, J. Bone Joint Surg. Am. 87 (2005) 260-267, doi:http://dx.doi.org/ 10.2106/JBJS.D.02043.

[11] P. Roussouly, S. Gollogly, E. Berthonnaud, J. Dimnet, Classification of the normal variation in the sagittal alignment of the human lumbar spine and pelvis in the standing position, Spine (Phila. Pa. 1976) 30 (13) (2005), doi:http://dx.doi.org/ 10.1097/01.brs.0000152379.54463.65 1558-9.

[12] J.R. Engsberg, K.H. Bridwell, A.K. Reitenbach, M.L. Uhrich, C. Baldus, K. Blanke, L.G. Lenke, Preoperative gait comparisons between adults undergoing long spinal deformity fusion surgery (thoracic to L4, L5, or sacrum) and controls, Spine (Phila. Pa. 1976) 26 (2001) 2020-2028, doi:http://dx.doi.org/10.1097/ 00007632-200109150-00016.

[13] D. Hirose, K. Ishida, Y. Nagano, T. Takahashi, H. Yamamoto, Posture of the trunk in the sagittal plane is associated with gait in community-dwelling elderly population, Clin. Biomech. 19 (2004) 57-63, doi:http://dx.doi.org/10.1016/j. clinbiomech.2003.08.005.

[14] P. Gottipati, S. Fatone, T. Koski, P.A. Sugrue, A. Ganju, Crouch gait in persons with positive sagittal spine alignment resolves with surgery, Gait Posture 39 (2014) 372-377, doi:http://dx.doi.org/10.1016/j.gaitpost.2013.08.012.

[15] V. Sarwahi, O. Boachie-adjei, S.I. Backus, Characterization of gait function in patients with postsurgical sagittal (Flatback) deformity a prospective study of 21 patients, Spine 27 (2002) 2328-2337, doi:http://dx.doi.org/10.1097/01. BRS.0000030304.83145.01.

[16] D.Y. Kim, E.S. Moon, J.O. Park, H.S. Chong, H.M. Lee, S.H. Moon, S.H. Kim, H.S Kim, The thoracic lordosis correction improves sacral slope and walking ability in neuromuscular scoliosis, J. Spinal Disord. Technol. 29 (8) (2013), doi:http:// dx.doi.org/10.1097/BSD.0b013e318294368e E413-20.

[17] R.B. Davis, S. Ounpuu, D. Tyburski, J.R. Gage, A gait analysis data collection and reduction technique, Hum. Mov. Sci. 10 (1991) 575-587, doi:http://dx.doi.org/ 10.1016/0167-9457(91)90046-Z.

[18] M. Benedetti, F. Catani, A. Leardini, E. Pignotti, S. Giannini, Data management in gait analysis for clinical applications, Clin. Biomech. 13 (1998) 204-215, doi: http://dx.doi.org/10.1016/S0268-0033(97)00041-7.

[19] H. Goujon, X. Bonnet, P. Sautreuil, M. Maurisset, L. Darmon, P. Fode, F. Lavaste, A functional evaluation of prosthetic foot kinematics during lower-limb amputee gait, Prosthet. Orthot. Int. 30 (2006) 213-223, doi:http://dx.doi.org/ 10.1016/S0966-6362(05)80254-1.

[20] M.M. a Janssen, X. Drevelle, L. Humbert, W. Skalli, R.M. Castelein, Differences in male and female spino-pelvic alignment in asymptomatic young adults: a three-dimensional analysis using upright low-dose digital biplanar X-rays, Spine (Phila. Pa. 1976) 34 (2009) E826-E832, doi:http://dx.doi.org/10.1097/ BRS.0b013e3181a9fd85.

[21] T. Vrtovec, F. Pernuš, B. Likar, A review of methods for quantitative evaluation of spinal curvature, Eur. Spine J. 18 (5) (2009) 593-607, doi:http://dx.doi.org/ 10.1007/s00586-009-0913-0.

[22] T. Vrtovec, M.M.A. Janssen, B. Likar, R.M. Castelein, M.A. Viergever, F. Pernuš, A review of methods for evaluating the quantitative parameters of sagittal pelvic alignment, Spine J. 12 (2012) 433-446, doi:http://dx.doi.org/10.1016/j. spinee 2012.02 .013

[23] F. Araújo, R. Lucas, N. Alegrete, A. Azevedo, H. Barros, Individual and contextual characteristics as determinants of sagittal standing posture: a populationbased study of adults, Spine J. (2014) 135-139, doi:http://dx.doi.org/10.1016/j. spinee.2014.01.040.

[24] J.M. Mac-Thiong, P. Roussouly, E. Berthonnaud, P. Guigui, Age- and sex-related variations in sagittal sacropelvic morphology and balance in asymptomatic adults, Eur. Spine J. 20 (2011) 1-6, doi:http://dx.doi.org/10.1007/s00586-0111923-2.

[25] E. Berthonnaud, J. Dimnet, P. Roussouly, H. Labelle, Analysis of the sagittal balance of the spine and pelvis using shape and orientation parameters, J. Spinal Disord. Technol. 18 (2005) 40-47, doi:http://dx.doi.org/10.1097/01. bsd.0000117542.88865.77.

[26] D. Kumar, C. Wyatt, K. Chiba, S. Lee, L. Nardo, T.M. Link, S. Majumdar, R.B. Souza, Anatomic correlates of reduced hip extension during walking in individuals with mild-moderate radiographic hip osteoarthritis, J. Orthop. Res. 33 (2015) 527-534, doi:http://dx.doi.org/10.1002/jor.22781.

[27] M. Leunig, P.E. Beaulé, R. Ganz, The concept of femoroacetabular impingement: current status and future perspectives, Clin. Orthop. Relat. Res. 467 (2009) 616-622, doi:http://dx.doi.org/10.1007/s11999-008-0646-0. 